\title{
Intensive Monitoring of Adverse Drug Reactions to Antiepileptic Drugs in Neurology Department of a Secondary Care Hospital in U.A.E
}

\author{
Hanin Jalal Alkhalil', Sathvik Belagodu Sridhar ${ }^{1, *}$, Syed Arman Rabbani ${ }^{1}$, Ammar Al Omar ${ }^{2}$ \\ 'Department of Clinical Pharmacy and Pharmacology, RAK College of Pharmaceutical Sciences (RAKCOPS), RAK Medical and Health Sciences University (RAKMHSU), \\ Ras Al-Khaimah, UAE. \\ 2Department of Neurology, Ibrahim Hamad Obaidallah Hospital, Ras Al Khaimah, UAE.
}

\begin{abstract}
Objective: The general objective of this study was to identify and evaluate adverse drug reactions (ADRs) associated with antiepileptic drugs. Methodology: This was a cross-sectional study, conducted in the neurology department of a secondary care hospital. All the patients meeting the inclusion criteria were identified and evaluated. Data were collected from the electronic medical records and was entered into a data collection. All ADRs identified and reported were evaluated for causality, severity, preventability and predictability using different standard scales. Results: A total of 24 ADRs was detected, documented, evaluated and reported during the study period. The incidence was found to be $10 \%$. Assessment of severity of the suspected ADRs revealed that $12 \%$ of suspected ADRs were mild level $1(54.2 \%)$ and level $2(41.7 \%)$. Causality assessment by WHO assessment scale reveals that majority of ADRs were considered as a probable 15 (62.5\%). Higher incidence of ADRs was documented in females (58.8\%). Central and peripheral nervous system was most commonly affected 09 $(37.5 \%)$ organ system. Sodium valproate was the most common drug mostly associated with ADRs. All $24(100 \%)$ of ADRs were definitely preventable. None of the demographic, disease or treatment-related factors
\end{abstract}

were significant $(p>0.05)$ predictors of ADRs. Conclusion: The findings of our study highlights the importance of regular monitoring and reporting of ADRs in the study setting. However, the study necessitates the importance of multicenter studies to further explore and evaluate the pattern of ADRs to different AEDs in the multiethnic population of U.A.E.

Key words: Antiepileptic drugs, Adverse drug reactions, Pharmacovigilance, Sodium Valproate, Ovarian Cyst.

\section{Correspondence}

Dr. Sathvik Belagodu Sridhar

Associate Professor, Chairperson-Incharge, Department of Clinical Pharmacy and Pharmacology, RAK College of Pharmaceutical Sciences (RAKCOPS), RAK Medical and Health Sciences University (RAKMHSU), Ras Al-Khaimah, UAE.

Phone: +971 072043000

Email: sathvik@rakmhsu.ac.ae

DOI: 10.5530/jyp.2019.11.40

\section{INTRODUCTION}

Adverse Drug Reactions (ADRs) are one of the significant cause of morbidity and mortality. It has been widely known that the occurrence of ADRs leads to nonadherence to medications, hospitalization, increased length of hospital stay, cost of therapy and poor quality of life. ${ }^{1}$ ADRs are the cause of $5 \%$ of all hospital admissions and it has been reported that $10-20 \%$ of inpatients are likely to experience at least one ADR during their hospital stay. ${ }^{2,3}$ Around $0.1-0.3 \%$ of ADRs are considered serious and are the cause of death of hospitalized patients. ${ }^{1}$ Due to various reasons, ADRs are often undetected or unreported, thus the actual incidence of ADRs may not be clear or greater than the reported rate. ${ }^{4}$

Antiepileptic Drugs (AEDs) are the main mode of drugs for treating epilepsy. In addition, some AEDs are used for the treatment of conditions such as neuropathic pain, migraine prophylaxis, fibromyalgia and in the treatment of certain psychiatric conditions such as bipolar disorder. ${ }^{5}$ The majority of the AEDs have the potential to cause mild to severe ADRs. ${ }^{67}$ Earlier Pharmacovigilance studies conducted in other parts of the world have documented a wide variety of ADRs to both old and new generation AEDs in different age groups and disease population. These studies have identified ADRs in $4.67 \%-31 \%$ in patients receiving different AEDs. ${ }^{8-12}$

There is a scarce in the published data regarding the incidence and pattern of ADRs to different AEDs in the local population. With this background, the main aim of the study was to identify and evaluate the ADRs associated with different antiepileptic drugs based on preventability, predictability and severity.

\section{MATERIALS AND METHODS}

\section{Study design and study setting}

This was a cross-sectional study conducted in neurology inpatient and outpatient departments of a secondary care hospital of Ras Al Khaimah, U.A.E. The data required for the study were collected for the period of seven months after obtaining the approval from the institutional and regional ethics and research committee approval [RAKMHSU-REC:92015-PG-P].

Patients who are more than 13 years of age and both the gender, who are diagnosed with epilepsy and managed with at least one AED, epilepsy patients with other co-morbidities on anti-epileptic drugs and non-epileptic patients (neuropathic pain, migraine etc.) who are on AEDs were included in the study. Hospitalized patients who are not managed with any AEDs, pediatric patients below 13 years of age and patients receiving AEDs in departments other than neurology were excluded.

The study investigator attended the outpatient clinics or ward rounds in the study site on a regular basis (i.e. thrice in a week). All the patients meeting the inclusion criteria were identified with the help of neurologist treating the patient. All clinical side effects/ADRs noted by the doctor and/ reported by patients during the outpatient visit and during admission were documented in an ADR reporting and documentation form, which includes various details such as demographic information, disease characteristics, history of ADR, medication history and other relevant information.

This is an open access article distributed under the terms of the Creative Commons Attribution-NonCommercial-ShareAlike 4.0 License, which allows others to remix, tweak, and build upon the work non-commercially, as long as the author is credited and the new creations are licensed under the identical terms. 


\section{Study tools and data analysis}

The causality assessment of documented ADRs was done using Naranjo and WHO probability scale. ${ }^{13,14}$ Severity was assessed using Hartwig et al. scale. ${ }^{15}$ While preventability assessment was done using Modified Schumock and Thornton"s Scale. ${ }^{16}$ Predictability assessment was done using predictability criteria. The study flow chart is represented in Figure 1.

\section{Statistical analysis}

The collected data was summated and was entered into the Microsoft Excel sheet and the data was analyzed using the Statistical Package for the Social Sciences (SPSS) version 24.0 [IBM, Armonk, New York, USA]. The categorical data were expressed as a percentage, while the continuous data were expressed as Mean \pm SD. The outcomes of interest were age, gender, number of medications prescribed, race, number of ADRs. The chi - square test was used to assess the association between various variables. The predictor of the occurrence of ADRs was tested using multivariate linear regression analysis. A probability value of $<0.05$ was considered as statistically significant.

\section{RESULTS}

\section{Incidence of ADRs}

A total of 170 patients meeting the inclusion criteria of the study were enrolled from the neurology outpatient and inpatient departments. A total of $24 \mathrm{ADRs}$ was reported in 17 patients. Hence the incidence rate of ADRs was found to be $[17 / 170$ patients $X 100]=10 \%$.

Higher incidence of ADRs was documented in females [10 (58.8\%)], compared to males [7 (41.18\%)]. The majority of the ADRs were reported in U.A.E nationals [14 (82.35\%)] followed by one ADR each in Comoron, Egyptian and Syrian national.

\section{Patient characteristics}

The average age of the patients who experienced ADRs is $32.8 \pm 18.7$ Years. A total of [16 (66.7\%)] ADRs was documented in patients receiving monotherapy, while [5 (20.8\%)] were associated with prescriptions of dual therapy and [3 (12.5\%)] with polytherapy prescriptions. The onset of reactions was found to be on the average of $57.7 \pm 54.7$ days after starting the treatment.

Among the neurological conditions in patients who developed ADRs, general epilepsy $(7,41.2 \%)$ was the most common, followed by unclassified epilepsy $(3,17.6 \%)$ and $2(11.8 \%)$ each in a migraine, focal epilepsy and neuropathy patients.

\section{Type and nature of ADRs}

Tremor and weight gain [3 (12.5\%)] were the most frequently reported ADRs, followed by hair loss, drowsiness, nervousness and irritability [2 (8.3\%)] each. Sodium valproate [10 (41.7\%)] was the most common AED responsible for causing ADRs, followed by levetiracetam [4 (16.7\%)] (Table 1 and 2).

\section{Causality, severity, preventability and predictability of ADRs}

The causality assessment based on Naranjo's scale reveals that a total of 17 (70.8\%) ADRs were probable, while the other 7 (29.2\%) ADRs were possible in nature. According to the WHO's scale, the majority of ADRs were considered as probable [15(62.5\%)], followed by certain types [9 (37.5\%)]. Most of the patients experienced mild ADRs of level 1 [13 (54.2\%)] and level 2 [10 (41.7\%)] and only one patient (4.2\%) had an ADR of moderate severity. All the 24 ADRs were not preventable and were found to be predictable in nature. Predisposing factors such as age and intercurrent disease [5(20.8\%)], intercurrent disease and multiple drug therapy $[5(20.8 \%)]$, intercurrent disease $[4(16.7 \%)]$ and gender [3 $(12.5 \%)]$ may associate with the occurrence of ADRs.

\section{Management of ADRs}

In the majority of the cases [11(45.8\%)] there was no management or change of the medication was done, after the occurrence of the ADRs. In $8(33.3 \%)$ ADR cases the drug was withdrawn, while in $5(20.8 \%)$ cases the dose was altered to manage the suspected ADRs. The majority of the ADRs were recovered in most of the patients [16(66.7\%)], followed by continuation type in 7 (29.2\%) patients and was unknown type in a single case. Dechallenge was done for most of the patients [16(66.7\%)] and definite improvement was observed in $[8(33.3 \%)]$ patients after the dechallenge. While no rechallenge was done for any of the 24 ADRs.

\section{Predictors of occurrence of ADRs}

None of the demographic and disease-related variables tested were associated with the occurrence of ADRs $(p>0.05)$ (Table 3 and 4 ).

\section{DISCUSSION}

The overall documented incidence of ADRs in our study was $10 \%$, which falls within the documented incidence rate range of earlier studies. In accordance with our findings, a study conducted by S RB et al. reported a $10.27 \%$ incidence rate. ${ }^{9}$ However, other studies have reported lower and a higher incidence rate of ADRs to AEDs compared to our study. ${ }^{6-8,10-12,17,18}$ The reasons for higher incidence of reported ADRs than Mathur S et al. could be due to the presence of study investigator/pharmacist during the patient interaction and history taking especially in outpatient settings. ${ }^{6}$ In addition, our study has documented all types of ADRs including minor and well-documented ones. However, some of the studies cited above have assessed only major ADRs, contributing to lower incidence rate. Furthermore, we have noticed that not all the patients report their ADRs voluntarily at the time of the visit to physician clinic. The reason for lower incidence rate than other studies could be due to smaller sample size and shorter study duration and the absence of established regular ADR monitoring and reporting system..$^{8,19}$

Our study indicates that sodium valproate was the most common AED causing ADRs. These results are in agreement with the study of Hansens $\mathrm{Y}$ et al. which showed that $44.44 \%$ of the ADRs were due to sodium valproate. ${ }^{20}$ In contrast, in a study conducted by Mathur S et al. phenytoin

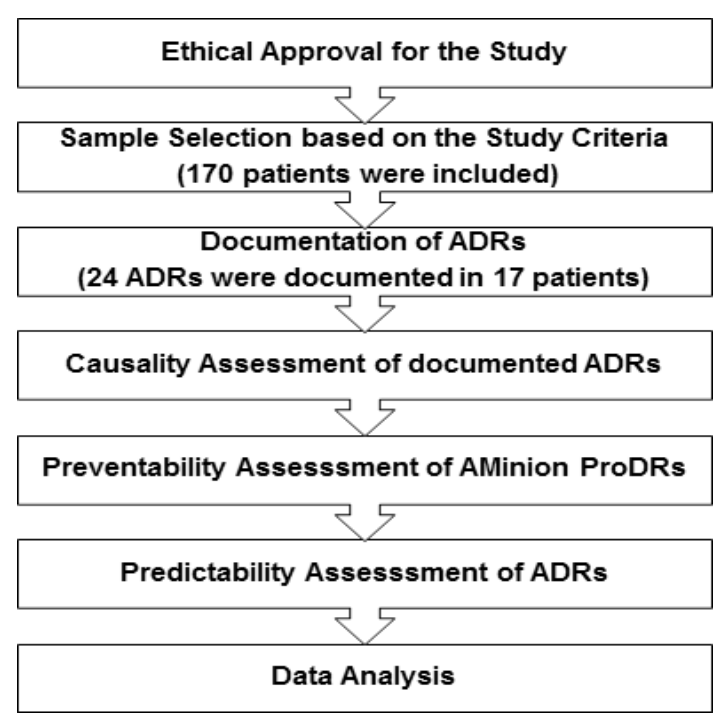

Figure 1: Flowchart of the Study. 
Table 1: ADRs and their suspected AEDs.

\begin{tabular}{ccc}
\hline ADRs & Associated Drugs & $n=24$ \\
\hline Tremor & Sodium Valproate & $3(12.5)$ \\
Weight gain & Sodium Valproate & $3(12.5)$ \\
Hair loss & Sodium Valproate & $2(8.3)$ \\
Drowsiness & Levetiracetam & $2(8.3)$ \\
Nervousness and Irritability & Levetiracetam & $2(8.3)$ \\
Ovarian Cyst & Sodium Valproate & $1(4.16)$ \\
Impaired liver function & Sodium Valproate & $1(4.16)$ \\
Drowsiness & Gabapentin & $1(4.16)$ \\
Agitation & Oxcarbazepine & $1(4.16)$ \\
Sleep disturbance & Topiramate & $1(4.16)$ \\
Weight loss & Topiramate & $1(4.16)$ \\
Paresthesia and Irritability & Topiramate & $1(4.16)$ \\
Drowsiness and Excessive sleep & Pregabalin & $1(4.16)$ \\
Suicidal thoughts and Depression & Phenobarbital & $1(4.16)$ \\
Irritability and Behavioral & Phenobarbital & $1(4.16)$ \\
Disturbances & & $1(4.16)$ \\
Dizziness & Carbamazepine & $1(4.16)$ \\
Peripheral Pain & Carbamazepine &
\end{tabular}

Table 2: System Organ Class (SOC) of Suspected ADRs based on : WHOART

\begin{tabular}{|c|c|c|}
\hline $\begin{array}{l}\text { System Organ Class } \\
\text { (WHO ART SOC Code) }\end{array}$ & Type of Suspected ADRs & $\begin{array}{l}n(\%) \\
n=24\end{array}$ \\
\hline $\begin{array}{c}\text { Central and peripheral } \\
\text { nervous system disorders } \\
(0410)\end{array}$ & $\begin{array}{c}\text { Somnolence/sedation/ } \\
\text { oversleep }(n=5) \\
\text { Tremor }(n=3) \\
\text { Dizziness }(n=1)\end{array}$ & $09(37.5 \%)$ \\
\hline $\begin{array}{l}\text { Gastro-intestinal system } \\
\text { disorders }(0600)\end{array}$ & Impaired liver function $(n=1)$ & $01(4.16 \%)$ \\
\hline $\begin{array}{l}\text { Metabolic and nutritional } \\
\text { disorders }(0800)\end{array}$ & $\begin{array}{l}\text { Weight gain }(n=3) \\
\text { Weight loss }(n=1)\end{array}$ & $04(16.7 \%)$ \\
\hline Psychiatric disorders (0500) & $\begin{array}{l}\text { Irritability and Odd behavior } \\
\qquad(n=4) \\
\text { Suicidal thoughts and } \\
\text { depression }(n=1) \text { Agitation } \\
(n=1)\end{array}$ & $06(25 \%)$ \\
\hline $\begin{array}{l}\text { Reproductive system disorders } \\
\qquad(1420)\end{array}$ & Ovarian cyst (1) & $01(4.16 \%)$ \\
\hline $\begin{array}{l}\text { Skin and Appendages } \\
\text { Disorder }(0100)\end{array}$ & Hair loss $(n=2)$ & $02(8.3 \%)$ \\
\hline $\begin{array}{c}\text { Musculoskeletal disorder } \\
(0200)\end{array}$ & Peripheral pain $(n=1)$ & $01(4.16 \%)$ \\
\hline
\end{tabular}

ADR: Adverse drug reaction, SOC: System-organ classification, WHO-ART: World Health Organization-adverse drug reaction.
Table 3: Association between Demographic Variables and Occurrence of ADRs.

\begin{tabular}{|c|c|c|c|c|}
\hline \multirow[t]{2}{*}{ Variable } & \multicolumn{2}{|c|}{ Occurrence of ADRs $n(\%)$} & \multirow[t]{2}{*}{$\mathbf{X}^{2}$} & \multirow[t]{2}{*}{$p$-value } \\
\hline & No & Yes & & \\
\hline \multicolumn{5}{|l|}{ Gender } \\
\hline Male & $77(50.3)$ & $7(41.2)$ & 0.512 & 0.474 \\
\hline Female & $76(49.7)$ & $10(58.8)$ & & \\
\hline \multicolumn{5}{|l|}{ Age (In Years) } \\
\hline $10-20$ & $25(16.3)$ & $3(17.6)$ & 3.075 & 0.688 \\
\hline $21-30$ & $46(30.1)$ & $4(23.5)$ & & \\
\hline $31-40$ & $30(19.6)$ & $6(35.3)$ & & \\
\hline $41-50$ & $16(10.5)$ & $2(11.8)$ & & \\
\hline $51-60$ & $23(15.0)$ & $1(5.9)$ & & \\
\hline$>60$ & $13(8.5)$ & $1(5.9)$ & & \\
\hline \multicolumn{5}{|l|}{ Nationality } \\
\hline Emirati & $107(69.9)$ & $14(82.4)$ & & \\
\hline Omani & $8(5.2)$ & $0(0.0)$ & 6.887 & 0.939 \\
\hline Egypt & $5(3.3)$ & $1(5.9)$ & & \\
\hline Palestinian & $6(3.9)$ & $0(0.0)$ & & \\
\hline Pakistan & $5(3.3)$ & $0(0.0)$ & & \\
\hline Comoron & $4(2.6)$ & $1(5.9)$ & & \\
\hline Yemeni & $3(2.0)$ & $0(0.0)$ & & \\
\hline Syrian & $2(1.3)$ & $1(5.9)$ & & \\
\hline Indian & $3(2.0)$ & $0(0.0)$ & & \\
\hline Bedouin & $3(2.0)$ & $0(0.0)$ & & \\
\hline Sudan & $3(2.0)$ & $0(0.0)$ & & \\
\hline Jordan & $1(0.7)$ & $0(0.0)$ & & \\
\hline Bahrain & $1(0.7)$ & $0(0.0)$ & & \\
\hline Iraqi & $1(0.7)$ & $0(0.0)$ & & \\
\hline Bangladeshi & $1(0.7)$ & $0(0.0)$ & & \\
\hline \multicolumn{5}{|l|}{ Diagnosis } \\
\hline General Epilepsy & $62(40.5)$ & $7(41.2)$ & 1.811 & 0.936 \\
\hline Migraine & $25(16.3)$ & $2(11.8)$ & & \\
\hline Focal Epilepsy & $21(13.7)$ & $2(11.8)$ & & \\
\hline Neuropathy & $19(12.4)$ & $2(11.8)$ & & \\
\hline Unclassified & $16(10.5)$ & $3(17.6)$ & & \\
\hline Focal secondary & $5(3.3)$ & $1(5.9)$ & & \\
\hline generalized & $5(3.3)$ & $0(0.0)$ & & \\
\hline \multicolumn{5}{|l|}{ Combination Type } \\
\hline $\begin{array}{l}\text { Number of } \\
\text { Medications }\end{array}$ & $93(60.8)$ & $13(76.5)$ & 1.953 & 0.582 \\
\hline One & $41(26.8)$ & $3(17.6)$ & & \\
\hline Two & $12(7.8)$ & $1(5.9)$ & & \\
\hline Three & $7(4.6)$ & $0(0.0)$ & & \\
\hline Four & & & & \\
\hline
\end{tabular}

was responsible for most of the ADRs. ${ }^{6}$ Also, the studies of Sebastian $\mathrm{J}$ et al. ${ }^{7}$ Jena $\mathrm{M}$ et al. ${ }^{18}$ and Habib $\mathrm{M}$ et al..$^{21}$ showed that phenytoin was responsible for $53.3 \%, 51.6 \%$ and $64 \%$, of the ADRs, respectively. The increase in the numbers of ADRs due to phenytoin in the previous studies is possibly due to the prescribing patterns of AED in those studies.

Tremor and weight gain was the most common ADRs experienced by the patients on AEDs, which was associated with sodium valproate and 
Table 4: Predictors of Occurrence of ADRs.

\begin{tabular}{ccccc}
\hline Variables & B & Beta & $\boldsymbol{t}$ & $\boldsymbol{P}$ \\
\hline Gender & 0.031 & 0.052 & 0.667 & 0.506 \\
Age & -0.008 & -0.041 & -0.529 & 0.597 \\
Nationality & -0.007 & -0.067 & -0.859 & 0.392 \\
Diagnosis & 0.005 & 0.029 & 0.375 & 0.708 \\
Number of & -0.037 & -0.100 & -1.300 & 0.195 \\
Medications & & & & \\
\hline
\end{tabular}

${ }^{\star} P<0.05$ is statistically significant.

this higher predominance could be due to the high incidence of sodium valproate used by patients in the present study. While GI disturbances were most common ADR reported in the study of Sebastian J et al. ${ }^{7}$ Whereas gum hyperplasia was mostly experienced by the patients enrolled in the study of Habib $\mathrm{M}$ et al. ${ }^{21}$ In the study of Hansens $\mathrm{Y}$ et al. vertigo was the highest $\mathrm{ADR}$ reported in $22.22 \%$ cases. ${ }^{20} \mathrm{CNS}$ related ADRs such as drowsiness and memory impairment was the most common ADRs documented in the studies of Mathur S et al. ${ }^{6}$ and Pal A et al. ${ }^{8}$ Hematological disturbances were found in $17.3 \%$ of the patients in Murthy V N et al. Study. ${ }^{22}$ While a headache was reported as the most common ADR in Rishe W et al. study in a percentage of $47.8 \%{ }^{17}$ and sedation in $37.7 \%$ of the patients in Jena M et al. study. ${ }^{6}$

The causality association was noted to be probable in nature in our study. Similarly, in the study of Sebastian J, et al. the association was probably in $73.33 \%$ and $48.88 \%$ two, as assessed by using WHO and Naranjo scales, respectively. ${ }^{7}$ Also in the study of Jena $\mathrm{M}$ et al. the association has been same at $62.2 \%$ as per WHO and $45.08 \%$ as per Naranjo scales. ${ }^{18}$ While in the study of Mathur S et al. The causal association was considered as possible according to the Naranjo and WHO assessment scales. ${ }^{6}$

Almost in consensus to our study, Sebastian J, et al. reported withdrawn of drug in $28.89 \%$ of the patients, the dose was altered in $11.11 \%$ of the patients and no change was done in $60 \%$ of the patients. ${ }^{7}$ Also in the study of Jena $\mathrm{M}$ et al. no change was done with the drug at $69.6 \%$ of the cases, dose altered was done to $14.75 \%$ of the cases and the drug was discontinued in $18.03 \%$ of the cases. ${ }^{18}$

Treatment was not given in any of the ADRs cases, neither in this study, nor the previous studies, as most of the cases were mild in nature and can be managed by altering the doses or withdrawing the drugs and other cases require no change in the AEDs, as the ADR will subside after the continuous use of the drug

A single case of the ovarian cyst was documented due to the use of sodium valproate. These findings are in accordance with another study, which reported polycystic ovaries in $16 \%$ of the patients receiving sodium valproate. ${ }^{23}$ Valproate known to induce androgen synthesis in the ovary, contributing for an ovarian cyst. ${ }^{24}$ This finding from our study is interesting and can be further explored.

None of the variables were significantly associated with or predictors of the occurrence of ADRs in our study. Few studies have documented age, gender, number of medications as the factors associated with ADRs. ${ }^{9,25,26}$ The strengths of our study being the data obtained provide an insight into the pattern of ADRs in a multiethnic population of U.A.E. Study has identified and documented few ADRs which could contribute to the existing Pharmacovigilance reporting system in the UAE. Further, the ADR monitoring and reporting creates the opportunity for the clinical pharmacist to work and contribute to the area of neurological disorders in the future.

\section{Study Limitations}

the main limitation of our study was a limited number of patients and short study duration and a minimum number of drugs were prescribed in the study setting. The number of patients who were admitted to the inpatient was very minimal compared to other studies. Language barrier with some patients, who cannot speak Arabic or English added difficulty in collecting important information regarding ADRs or pattern of another drug user.

\section{CONCLUSION}

Most ADRs documented in our study were mild in nature. The findings of our study highlight the importance of regular monitoring and reporting of ADRs in the study setting. However, the study necessitates the importance of multicenter studies to further explore and evaluate the pattern of ADRs to different AEDs in the multiethnic population of U.A.E.

\section{ACKNOWLEDGEMENT}

Our sincere thanks to Dr. Padma GM Rao, Dean RAKCOPS for all the support. Our heartfelt thanks to Dr. Mohammed Tawfik and Dr. Khalid Al Shamsi, consultant Neurologists of Ibrahim Bin Hamad Obaidallah Hospital for their kind support throughout the study period. We extend our sincere thanks to Dr. Gurumadhva Rao, President of RAKMHSU for all the support and encouragement.

\section{CONFLICT OF INTEREST}

The authors declare no conflict of interest.

\section{ABBREVIATIONS}

ADR: Adverse Drug Reaction; AED: Anti-Epileptic Drug; CNS: Central Nervous System; GI: Gastrointestinal; UAE: United Arab Emirates; WHO: World Health Organization.

\section{REFERENCES}

1. Schatz SN, Weber RJ. Adverse drug reactions. ACCP (American College of Clinical Pharmacy). CNS/Pharmacy Practice, PSAP. 2015. Available from: https:// www.accp.com/docs/bookstore/psap/2015B2. SampleChapter.pdf

2. Kongkaew C, Noyce PR, Ashcroft DM. Hospital Admissions Associated with Adverse Drug Reactions: A Systematic Review of Prospective Observational Studies. Ann Pharmacotherapy. 2008;42(7-8):1017-25.

3. Lundkvist J, Jonsson B. Pharmacoeconomics of adverse drug reactions. Fundam Clin Pharmacol. 2004;18(3):275-80.

4. Lazarou J, Pomeranz BH, Corey PN. The incidence of adverse drug reactions in hospitalized patients. JAMA. 1998;279(15):1200-5

5. Bialer M. Why are antiepileptic drugs used for nonepileptic conditions?. Epilepsia. 2012;53(7):26-33.

6. Mathur S, Sen S, Ramesh L, Kumar MS. Utilization Pattern of Antiepileptic Drugs and Their Adverse Effects, in a Teaching Hospital. Asian J Pharm Clin Res. 2010;3(1):55-9.

7. Sebastian J, Adepu R, Keshava BS, Harsha S. Assessment of Antiepileptic Drugs Usage in a South Indian Tertiary Care Teaching Hospital. Neurology Asia. 2013;18(2):159-65.

8. Anderson M, Egunsola O, Cherrill J, Millward C, Fakis A, Choonara I. A prospective study of adverse drug reactions to antiepileptic drugs in children. BMJ Open. 2015;5(6):e008298

9. S RB, Narayan SS, Sharma GR, Rodrigues RJ, Kulkarni C. Pattern of adverse drug reactions to antiepileptic drugs: a cross-sectional one-year survey at a tertiary care hospital. Pharmacoepidemiol Drug Saf. 2008;17(8):807-12.

10. Akalu SD, Belavadi NG. The pattern of adverse drug reaction to antiepileptic drugs in a tertiary care hospital. Int J Basic Clin Pharmacol. 2017;6(9):2219-23.

11. Fricke-Galindo I, Jung-Cook H, Llerena A, López-López M. Pharmacogenetics of adverse reactions to antiepileptic drugs. Neurología. 2018;33(3):165-76.

12. Hilgers A, Schaefer M. Systematic Adverse Drug Reaction Monitoring of $\mathrm{Pa}$ tients Under Newer Antiepileptic Drugs Using Routine Clinical Data of Inpatients. Drugs Real World Outcomes. 2016;3(2):209-21.

13. Naranjo CA, Busto U, Sellars EM, Sandor P, Ruiz I, Roberts EA, et al. Method for Estimating the Probability of Adverse Drug Reactions. Clin Pharmacol Ther 1981;30(2):239-45. 
14. The use of the WHO-UMC system for standardized case causality assessment. Available from: http://www.WHO-UMC.org/graphics/4409.pdf.

15. Hartwig SC, Siegel J, Schneider PJ. Preventability and severity assessment in reporting adverse drug reactions. Am J Hosp Pharm. 1992;49(9):2229-32.

16. Schumock GT, Thornton JP. Focusing on the preventability of adverse drug reactions. Hosp Pharm. 1992;27(6):538.

17. Rishe W, Seifu MF, Gelaw BK, Gunasekaran T, Gebremariam ET, Mohammed MA. Drug use evaluation of antiepileptic drugs in outpatient epilepsy clinic of bishoft general hospital, East Shoa, Ethiopia. Int Res Dev Pharm L Sci. 2015;4(3):1516-28.

18. Jena M, Jena S, Dash M. Monitoring of Prescriptions and Pharmacovigilance Evaluation of Antiepileptic Drugs in a Tertiary Care Teaching Hospital. Int J Pharm Sci Rev Res. 2014;29(1):99-104.

19. Pal AB, Prusty SK, Sahu PK, Swain T. Drug utilization pattern of antiepileptic drugs: A pharmacoepidemiologic and pharmacovigilance study in a tertiary teaching hospital in India. Asian J Pharm Clin Res. 2011;4(1):96-9.

20. Hanssens Y, Deleu D, AlBalushi K, AlHashar A, Al-Zakwani I. Drug Utilization Pattern of Anti-Epileptic Drugs: A Pharmacoepidemiologic Study in Oman. J Clin Pharm Ther. 2002;27(5):357-64.

21. Habib M, Khan S, Hoque A, Mondal M, Hasan A, Chowdhury RN, et al. Antiepileptic Drug Utilization in Bangladesh: Experience from Dhaka Medical College
Hospital. BMC Res Notes. 2013;6(1):473.

22. Murthy NV, Anusha B, Perumal P. A Study on trends in prescribing pattern of anti-epileptic drugs in tertiary care teaching hospital. Int J Che Pharmace Sci. $2012 ; 3(2): 25-30$

23. Prabhakar S, Sahota P, Kharbanda PS, Siali R, Jain V, Lal V. et al. Sodium Valproate, Hyperandrogenism and Altered Ovarian Function in Indian Women with Epilepsy: A Prospective Study. Epilepsia. 2007;48(7):1371-7.

24. Harden CL. Polycystic Ovaries and Polycystic Ovary Syndrome in Epilepsy: Evidence for Neurogonadal Disease. Epilepsy Curr. 2005;5(4):142-6.

25. Karimzadeh P, Bakrani V. Antiepileptic Drug-Related Adverse Reactions and Factors Influencing These Reactions. Iran J Child Neurol. 2013;7(3):25-9.

26. Mannesse CK, Derkx FH, DeRidder MA, Veld AJMI, DerCammen TJV. Contribution of adverse drug reactions to hospital admission of older patients. Age Ageing. 2000;29(1):359

Article History: Submission Date : 15-11-2018; Revised Date : 16-02-2019; Acceptance Date : 21-02-2019.

Cite this article: Alkhalil HJ, Sridhar SB, Rabbani SA, Omar AA. Intensive Monitoring of Adverse Drug Reactions to Antiepileptic Drugs in Neurology Department of a Secondary Care Hospital in U.A.E. J Young Pharm. 2019;11(2):192-6. 